\title{
Auditory Outcome of Cochlear Implantation in Adolescent and Adult Patients with Enlarged Vestibular Aqueduct and Biallelic SLC26A4 Mutations
}

\author{
Mee Hyun Song', Jee Eun Yoo ${ }^{1,2}$, Jae Young Choi ${ }^{2}$, and Hyun Seung Choi ${ }^{3}$ \\ ${ }^{1}$ Department of Otorhinolaryngology, Myongii Hospital, Seonam University College of Medicine, Goyang; and \\ ${ }^{2}$ Department of Otorhinolaryngology, Yonsei University College of Medicine, Seoul; and ${ }^{3}$ Department of Otorhinolaryngology, \\ National Health Insurance Service Ilsan Hospital, Goyang, Korea
}

\author{
SLC26A4 변이를 가진 전정수도관 확장증 환자에서 청년기와 성인기에 시행된 인공와우이식술의 결과 \\ 송미현 ${ }^{1} \cdot$ 유지은 $^{1,2} \cdot$ 최재영 ${ }^{2} \cdot$ 최현승 $^{3}$ \\ 서남대학교 의과대학 명지병원 이비인후과학교실, ${ }^{1}$ 연세대학교 의과대학 이비인후과학교실 ${ }^{2}$ 국민건강보험 일산병원 이비인후과 ${ }^{3}$
}

Received June 12, 2017

Revised July 24, 2017

Accepted August 14, 2017

Address for correspondence

Hyun Seung Choi, MD

Department of Otorhinolaryngology,

National Health Insurance Service

Ilsan Hospital, 100 Ilsan-ro,

Ilsandong-gu, Goyang 10444, Korea

Tel $+82-31-900-0972$

Fax $+82-31-900-0343$

E-mail choihyunseung@gmail.com
Background and Objectives Mutations of the SLC26A4 gene cause congenital hearing loss and enlarged vestibular aqueduct (EVA). A considerable proportion of patients with $S L$ C26A4 mutations have significant residual hearing at birth that eventually worsen and become the cause for cochlear implantation (CI) later in their adolescence or adulthood. We analyzed the auditory outcome and prognostic factors of CI in patients with EVA and biallelic SLC26A4 mutations showing progressive early-onset hearing loss, who eventually had implantation in their adolescent or adult periods.

Subjects and Method Sixteen patients with EVA carrying biallelic SLC26A4 mutations who received CI after 12 years of age were included for analysis. The outcome and prognostic factors of CI were analyzed. The postoperative follow-up period ranged from 3 to 48 months. Results The age at CI ranged from 12 to 44 years. The categories of auditory performance score was significantly improved after CI from 3.1 to $4.9(p<0.05)$. The mean sentence scores improved significantly in the auditory-visual and auditory-only conditions $(p<0.05)$. The significant prognostic factors were measurable bone conduction thresholds, preoperative residual hearing, recent history of sudden aggravation of hearing loss, and preoperative speech intelligibility rating scores. There was a tendency of lower postoperative sentence scores in the group with homozygous H723R mutation, but statistical significance was not reached.

Conclusion Despite the early-onset of hearing loss, significant improvement in auditory performance can be expected after CI in adolescent and adult patients with EVA and biallelic SLC26A4 mutations. Significant prognostic factors should be considered in selecting candidates and preoperative counseling for $\mathrm{CI}$.

Korean J Otorhinolaryngol-Head Neck Surg 2017;60(12):605-13

Key Words Adolescent · Adult · Cochlear implantation · Enlarged vestibular aqueduct . SLC26A4.

\section{Introduction}

Mutations of the SLC26A4 gene cause nonsyndromic re- cessive hearing loss DFNB4 or Pendred syndrome." These patients demonstrate congenital hearing loss and enlarged vestibular aqueduct (EVA) on the temporal bone computed

This is an Open Access article distributed under the terms of the Creative Commons Attribution Non-Commercial License (http://creativecommons.org/licenses/by-nc/4.0) which permits unrestricted non-commercial use, distribution, and reproduction in any medium, provided the original work is properly cited. 
tomography (CT), with the addition of a thyroid phenotype in Pendred syndrome. ${ }^{1)}$ Unlike most forms of autosomal recessive type of hearing loss that show congenital severe to profound hearing loss, considerable proportion of patients with SLC26A4 mutations have significant residual hearing at birth that eventually worsen. ${ }^{2)}$ Thus, many of these patients use hearing aids initially and become candidates for cochlear implantation (CI) in the 2nd or 3rd decade. ${ }^{3)} \mathrm{CI}$ in patients with EVA has been successfully performed since the first report by Slattery and Luxford ${ }^{4)}$ in 1995, and many studies have reported excellent auditory outcome without surgical complications mostly in children. ${ }^{5-8)}$ Considering the favorable outcome of CI in patients with EVA, there are not many reports on the prognostic factors for auditory outcome after $\mathrm{CI}$ in these patients. A recent study suggested that children with isolated EVA demonstrated better speech performance following CI compared to those with concomitant cochlear anomalies, although statistical significance was not reached. ${ }^{9)}$

When managing hearing loss in patients with EVA, special patient characteristics have to be considered. There is a wide variability concerning the degree of residual hearing in the prelingual period that either progress gradually or suddenly aggravate in the adolescent or adult period. ${ }^{3,7)}$ The time point of when their hearing worsens to severe to profound hearing loss is related to the level of exposure to speech prior to CI, which varies greatly among patients with EVA. Therefore, this group of patients should be distinguished from prelingually deaf patients with delayed implantation or postlingually deaf adults. In an audiological aspect, patients with EVA usually have an air-bone gap in the low frequencies due to the third window effect that can also influence the outcome of CI. ${ }^{3)}$

Although patients with EVA should not be considered equivalent to prelingually deaf patients, these patients with early-onset hearing loss undergoing CI in the adolescent or adult period need special attention and individualized strategies for auditory rehabilitation. Prognostic factors related to auditory performance after CI in prelingually deaf adults should also be carefully evaluated in these patients, including age at onset of hearing loss, age at implantation, duration of deafness, mode of communication, degree of residual hearing, use of hearing aids, and speech intelligibility. ${ }^{10-13)}$

Despite the fact that EVA can result from various causes, most of the previous studies reporting the outcome of CI in patients with EVA have not included the genetic data. ${ }^{6-9,14,15)}$ A study by Mey, et al. ${ }^{16)}$ included the results of genetic analysis but only reported the surgical outcome and complications of CI in patients with EVA. Lai, et al. ${ }^{17)}$ reported the results of SLC26A4 mutations but did not compare the outcome of $\mathrm{CI}$ according to mutation types. In this study, we analyzed the outcome of CI in patients with EVA caused by biallelic SLC26A4 mutations who were implanted in their adolescent or adult periods, and also evaluated the various prognostic factors of postoperative auditory performance after CI in order to aid in candidacy selection and patient counseling. In addition, the genetic data of SLC26A4 mutations were correlated with outcome.

\section{Subjects and Method}

\section{Subjects}

This study included 16 patients demonstrating EVA on temporal bone CT who received CI after the age of 12 years. All of the included patients were confirmed to have biallelic SLC26A4 mutations as the cause of hearing loss and EVA. The age of patients at CI ranged from 12 to 44 years and the male to female ratio was 7:9. Eight patients were implanted with Nucleus devices (CI24RE; Cochlear Ltd., Sydney, Australia) while six and two patients were implanted with Clarion (HiRes 90k; Advanced Bionics, Los Angeles, CA, USA) and MED-EL (Innsbruck, Austria) (1 Sonata, 1 Concerto) devices, respectively. This study was approved by the Institutional Review Board of the author's medical center (2015-1508-001).

\section{Genetic analysis}

Mutational analysis of the SLC26A4 gene was performed as previously described. ${ }^{18)}$ DNA was extracted from EDTA whole blood with an Easy-DNATM Kit (Invitrogen Corporation, Carlsbad, CA, USA). The concentration and quality of genomic DNA was evaluated by Nanodrop (ND-1000; Thermo Scientific, Wilmington, DE, USA). The primers designed to amplify 20 exons and flanking introns of the SLC26A4 are available upon request. Polymerase chain reaction (PCR) was performed on $100 \mathrm{ng}$ of genomic DNA using an AccuPower ${ }^{\mathrm{TM}}$ Premix (Bioneer Co., Daejeon, Korea) under the following amplification conditions: $94^{\circ} \mathrm{C}$ for $3 \mathrm{~min}$ followed by $50 \mathrm{cy}-$ cles of $94^{\circ} \mathrm{C}$ for $1 \mathrm{~min}, 62^{\circ} \mathrm{C}$ for $10 \mathrm{sec}$ and $72^{\circ} \mathrm{C}$ for $15 \mathrm{sec}$, and final extension was at $72^{\circ} \mathrm{C}$ for $15 \mathrm{~min}$. The PCR products were then purified using a QIAquick Gel Extraction Kit (Qiagen, Düsseldorf, Germany) and directly sequenced using a cycle method with the same primers for PCR and a Big Dye Terminator Cycle Sequencing Ready Reaction Kit (Applied Biosystems, Foster City, CA, USA) with following conditions: $96^{\circ} \mathrm{C}$ 
for $5 \mathrm{~min}$ followed by 24 cycles of $96^{\circ} \mathrm{C}$ for $10 \mathrm{sec}, 50^{\circ} \mathrm{C}$ for 5 sec and $60^{\circ} \mathrm{C}$ for $4 \mathrm{~min}$ and final extension at $72^{\circ} \mathrm{C}$ for $5 \mathrm{~min}$, in conjunction with an ABI Prism 3500 Dx automated genetic analyzer (Applied Biosystems).

\section{Analysis of outcome of cochlear implantation}

Categories of auditory performance (CAP) scores, mono-/ bi-syllable word scores, and sentence scores were measured preoperatively and postoperatively. The word and sentence scores were measured in the auditory-only (AO) and auditoryvisual (AV) conditions. Postoperative improvement of each measure was analyzed for statistical significance. The followup period ranged from 3-48 months after switch-on.

\section{Evaluation of clinical and audiologic factors}

Factors that could influence the outcome of CI were analyzed. Concerning the use of hearing aids, factors including the age at initial use, the site, and whether there was recent usage before CI were analyzed. The progressive nature of hearing loss was evaluated in which patients were asked about a definite history and timing of sudden aggravation of hearing loss. The speech intelligibility rating (SIR) was evaluated preoperatively (scale $0-5)$. ${ }^{19)}$ Preoperative residual hearing was analyzed by measuring pure tone average (PTA, average of air conduction thresholds at $0.5,1,2$, and $4 \mathrm{kHz}$ ) and bone conduction thresholds. In addition, the main com- munication mode was investigated and categorized into auditory or sign communication.

\section{Statistical analysis}

Statistical analysis was performed using SPSS version 18 software (SPSS Inc., Chicago, IL, USA). The improvement in preoperative and postoperative CAP scores, word and sentences scores were analyzed by Wilcoxon Signed-Rank test. Mann-Whitney U test was used for comparison of postoperative sentence scores (AO condition) regarding factors including the presence or absence of measurable bone conduction, a recent history of sudden aggravation of hearing loss, and the thyroid phenotype. Spearman's rank correlation was used to analyze the correlation between the postoperative outcome and other factors including age, preoperative PTA, and preoperative SIR scores. Kruskal-Wallis test was used for comparison of outcome according to the type of $S L$ $C 26 A 4$ mutations. $p<0.05$ was considered significant.

\section{Results}

\section{Clinical and audiologic characteristics}

Clinical characteristics of the patients are summarized in Table 1. The patients were fitted with a hearing aid at a mean age of 6.5 years (range: 2-27 years). Eleven of 16 patients (69\%) used bilateral hearing aids. Two patients (patients 9 and 11)

Table 1. Clinical and genetic data of the patients

\begin{tabular}{|c|c|c|c|c|c|c|c|c|c|}
\hline No. & Age at $\mathrm{Cl}$ & Sex & $\mathrm{Cl}$ site & Device & SLC26A4 mutations & $\begin{array}{c}\mathrm{HA} \\
\text { (age, site) }\end{array}$ & $\begin{array}{l}\text { Sudden } \\
\text { aggravation of } \mathrm{HL}^{*}\end{array}$ & SIR & $\begin{array}{l}\text { Cochlear } \\
\text { anomaly }\end{array}$ \\
\hline 1 & 44 & $\mathrm{~F}$ & $R$ & MED-EL & $\mathrm{H} 723 \mathrm{R} / \mathrm{T} 410 \mathrm{M}$ & $11 Y, B$ & $2 Y$ & 4 & IP $\|$ \\
\hline 2 & 18 & $\mathrm{~F}$ & $\mathrm{~L}$ & Nucleus & L676Q/IVS7-2A>G & $2 Y, B$ & $<1 Y$ & 4 & $\mid \mathrm{P}-\|$ \\
\hline 3 & 13 & $\mathrm{~F}$ & $R$ & Nucleus & IVS7-2A>G/IVS7-2A>G & $3 Y, B$ & $<1 Y$ & 5 & $\mid \mathrm{P}-\mathrm{I}$ \\
\hline 4 & 23 & $\mathrm{~F}$ & $R$ & Clarion & $\mathrm{H} 723 \mathrm{R} / \mathrm{H} 723 \mathrm{R}$ & $4 Y, B$ & - & 3 & $\mid \mathrm{P}-\|$ \\
\hline 5 & 25 & $\mathrm{~F}$ & $R$ & Clarion & $\mathrm{H} 723 \mathrm{R} / \mathrm{IVS7}-2 \mathrm{~A}>\mathrm{G}$ & $4 Y, B$ & - & 4 & $\mid \mathrm{P}-\mathrm{I}$ \\
\hline 6 & 12 & M & L & Clarion & $\mathrm{H} 723 \mathrm{R} / \mathrm{T} 178 \mathrm{P}$ & $4 Y, B$ & $<1 Y$ & 3 & $\mid \mathrm{P}-\|$ \\
\hline 7 & 29 & M & $R$ & Nucleus & $\mathrm{H} 723 \mathrm{R} / \mathrm{H} 723 \mathrm{R}$ & $11 Y, R$ & - & 2 & $\mid \mathrm{P}-\mathrm{I}$ \\
\hline 8 & 21 & $\mathrm{~F}$ & $R$ & Nucleus & $\mathrm{H} 723 \mathrm{R} / \mathrm{H} 723 \mathrm{R}$ & $11 \mathrm{Y}, \mathrm{L}$ & $3 Y$ & 4 & $\mid \mathrm{P}-\mathrm{I}$ \\
\hline 9 & 37 & $\mathrm{~F}$ & $R$ & Nucleus & $\mathrm{H} 723 \mathrm{R} / \mathrm{IVS} 7-2 \mathrm{~A}>\mathrm{G}$ & $27 Y^{\dagger}, B$ & - & 2 & $\mid \mathrm{P}-\mathrm{II}$ \\
\hline 10 & 32 & $\mathrm{~F}$ & L & Nucleus & H723R/Arg677Alafs & $9 Y, B$ & - & 4 & IP-II \\
\hline 11 & 34 & M & $R$ & Clarion & H723R/F572L & $2 Y^{\dagger}, R$ & - & 3 & $\mid \mathrm{P}-\|$ \\
\hline 12 & 32 & M & $R$ & Clarion & $\mathrm{H} 723 \mathrm{R} / \mathrm{IVS} 7-2 \mathrm{~A}>\mathrm{G}$ & $3 Y, L$ & - & 3 & $\mid \mathrm{P}-\|$ \\
\hline 13 & 31 & $\mathrm{~F}$ & $\mathrm{~L}$ & Clarion & $\mathrm{H} 723 \mathrm{R} / \mathrm{H} 723 \mathrm{R}$ & $4 Y, R$ & - & 4 & $\mid \mathrm{P}-\|$ \\
\hline 14 & 16 & M & $R$ & Nucleus & IVS7-2A>G/IVS7-2A>G & $2 Y, B$ & - & 3 & - \\
\hline 15 & 17 & M & $R$ & Nucleus & H723R/V138L & $3 Y, B$ & $<1 Y$ & 4 & |P-|| \\
\hline 16 & 18 & M & $R$ & MED-EL & $\mathrm{H} 723 \mathrm{R} / \mathrm{M} 147 \mathrm{~V}$ & $3 Y, B$ & $2 Y$ & 5 & $\mid \mathrm{P}-\|$ \\
\hline
\end{tabular}

*duration in years before $\mathrm{Cl}$ when the sudden aggravation of hearing loss occurred, ttemporary use of hearing aids but discontinued use of hearing aids prior to $\mathrm{Cl}$ due to limited benefit. Cl: cochlear implantation, HA: hearing aids, HL: hearing loss, SIR: speech intelligibility rating, IP-II: incomplete partition type II, F: female, M: male, R: right, L: left, Y: years, B: both 
had used hearing aids for a short period of time but discontinued their use due to limited benefit. Only one patient (patient 7) used sign language and others communicated using the auditory modality with or without the aid of lip reading. All of the patients exhibited prelingual or perilingual onset of hearing loss of variable degree which had progressed. Seven of 16 patients (44\%) experienced sudden aggravation of hearing loss which occurred within 3 years before CI. The mean value for SIR measured preoperatively was 3.5, ranging from 2-5 (Table 1).

\section{Genetic analysis of the SLC26A4 gene}

Four patients (25\%) demonstrated H723R homozygous mutations. Nine patients (56\%) carried compound heterozygous mutations having H723R on one allele and other type of mutations on the other (Table 1). The second most common mutation was IVS7-2A $>\mathrm{G}$, identified in homozygous form in two patients and in compound heterozygous form in 4 patients. The allelic frequencies for the two most commons mutations of SLC26A4 were 53\% (17/32) for H723R and 25\% (8/32) for IVS7-2A $>$ G. Mutations other than these two most common mutations were missense mutations except for one frameshift mutation (patient 10).

\section{Overall postoperative auditory outcome after cochlear implantation}

The CAP score was significantly improved after CI from 3.1 to 4.9 ( $p<0.05)$ (Fig. 1). The monosyllable, bisyllable word scores and sentence scores improved significantly in the AV and $\mathrm{AO}$ conditions $(p<0.05)$ (Fig. 2). The mean postoperative scores for monosyllable, bisyllable, and sentence scores were 71, 76, and 84\%, respectively, in the AV condition (Fig. 2A). Those scores in the AO condition were 30,39 , and $52 \%$, respectively (Fig. 2B). Of the six patients who did not show significant improvement in the $\mathrm{AO}$ condition (posteroperative AO sentence score $<40 \%$ ), all but one patient (patient 9) demonstrated significant improvement in the AV condition.

\section{Factors related to postoperative auditory outcome after cochlear implantation}

Various factors that may be related to the outcome after CI were analyzed. First, the preoperative PTA in the better ear was demonstrated to have significant correlation to postoperative outcome (Fig. 3). The presence or absence of measurable bone conduction in at least one frequency of the ipsilateral ear was evaluated and correlated with postoperative sentence scores in the AO condition (Fig. 4). The postoperative sentence score was significantly higher when there was measurable bone conduction in at least one frequency usually in the low frequencies. When there was a definite history of sudden aggravation of hearing loss seen, significantly better postoperative sentence scores could be achieved (Fig. 5). Seven patients had a recent history of sudden aggravation of hearing loss, within 3 years prior to CI, which did not improve with steroid treatment. The preoperative SIR scores correlated significantly with the postoperative outcome, in which pa-
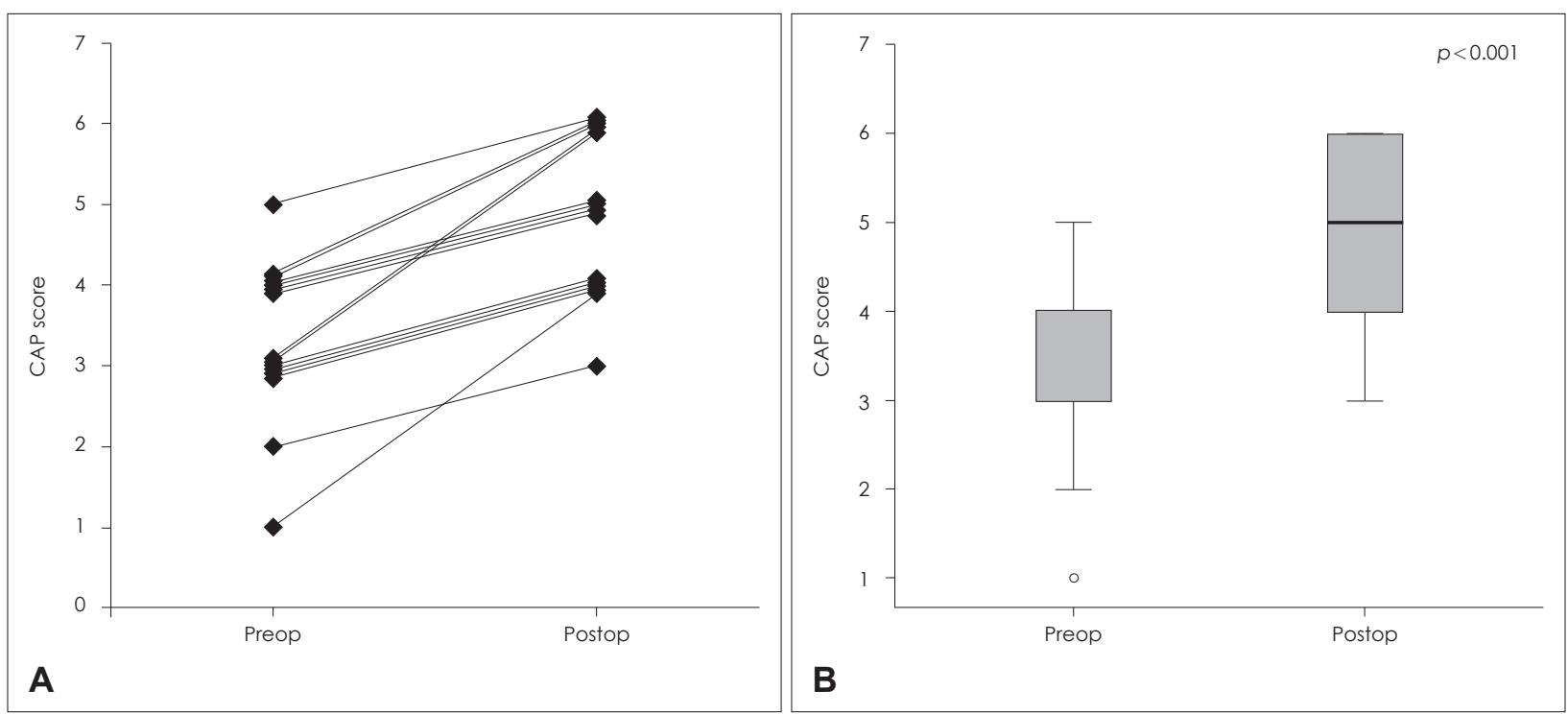

Fig. 1. The preoperative and postoperative CAP scores in patients with biallelic SLC26A4 mutation. The individual data show that CAP scores were improved in all of the patients $(A)$. The improvement in CAP scores was statistically significant $(p<0.001)(B)$. CAP: categories of auditory performance, preop: preoperative, postop: postoperative. 

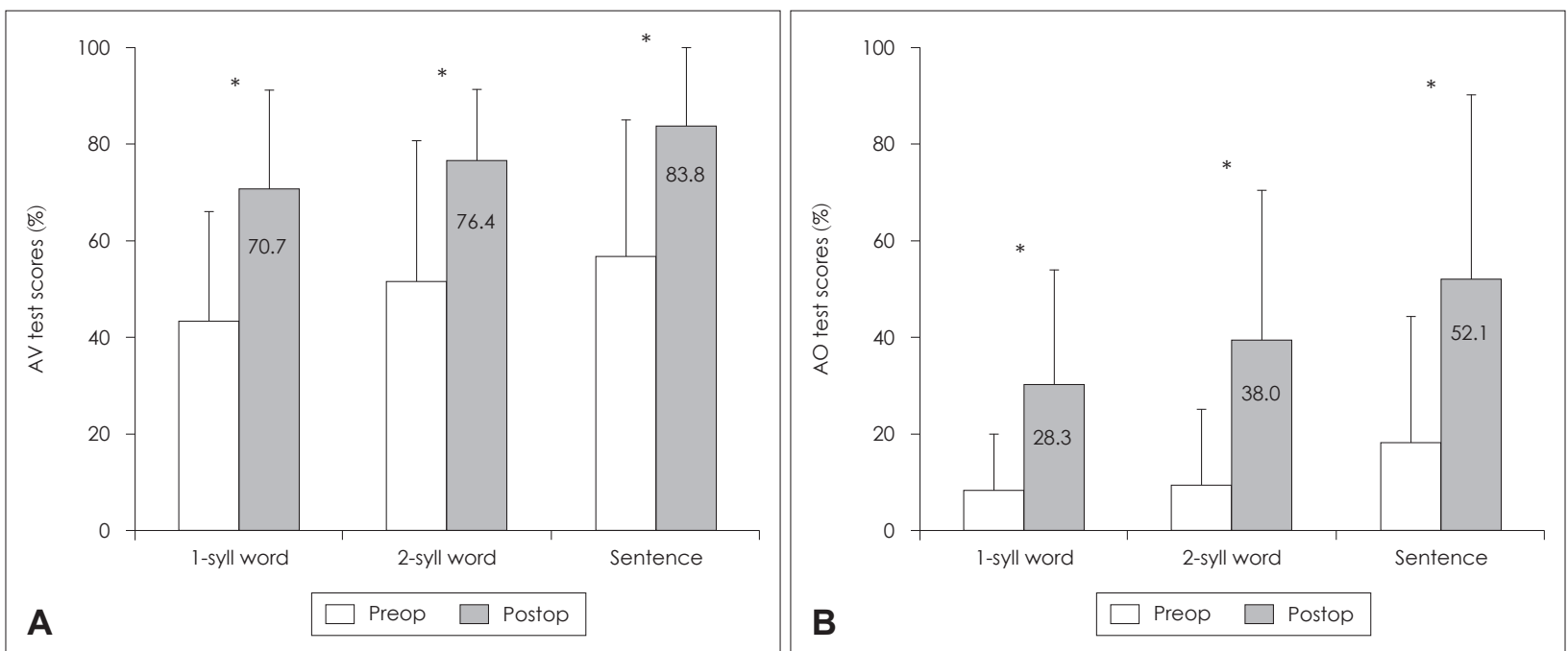

Fig. 2. The preoperative and postoperative values for monosyllable and bisyllable word scores and sentence scores in (A) AV condition and (B) AO condition. Statistically significant improvement was demonstrated in monosyllable and bisyllable word scores and sentence scores in both AV and AO conditions $(p<0.05)$. ${ }^{*} p<0.05$. AV: auditory-visual, AO: auditory-only, 1-syll: monosyllable, 2-syll: bisyllable, preop: preoperative, postop: postoperative.

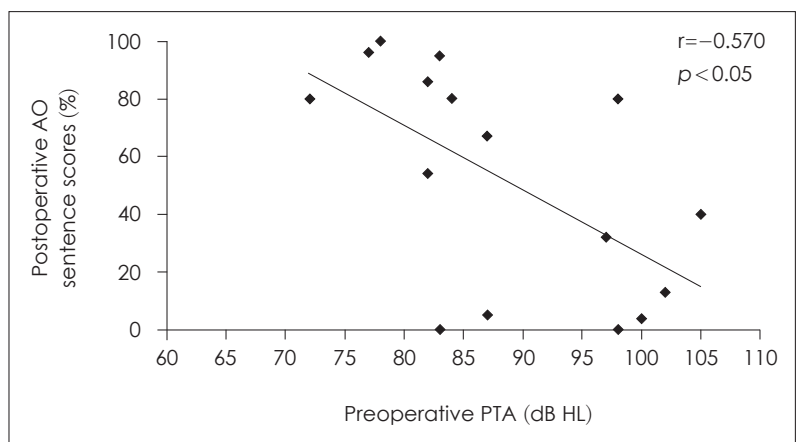

Fig. 3. The correlation between preoperative residual hearing and postoperative outcome. The preoperative pure tone average values ( $\mathrm{dB} \mathrm{HL}$ ) demonstrated significant correlation to postoperative sentence scores in auditory-only condition $(r=-0.570, p=0.021)$. AO: auditory-only, PTA: pure tone average.

tients with an SIR score of 2 demonstrated poor postoperative outcome while those with an SIR score of 5 showed high postoperative sentence scores (Fig. 6).

Age at CI did not show significant correlation to postoperative outcome ( $\mathrm{r}=-0.427, p=0.099)$. The type of SLC26A4 mutations was divided into 3 groups including H723R homozygous, H723R compound heterozygous, and other mutations. There was a clear tendency of lower postoperative sentence scores in the group with H723R homozygous mutation, but statistical significance was not reached ( $p>0.05)$ (Fig. 7).

Other factors that may have influenced the outcome were the use of sign language $(n=1)$ and nonuse of hearing aids before CI $(n=2)$. Patient 7 who was implanted at 29 years of age, was the only patient who used sign language together with the auditory modality for communication and had used a hear-

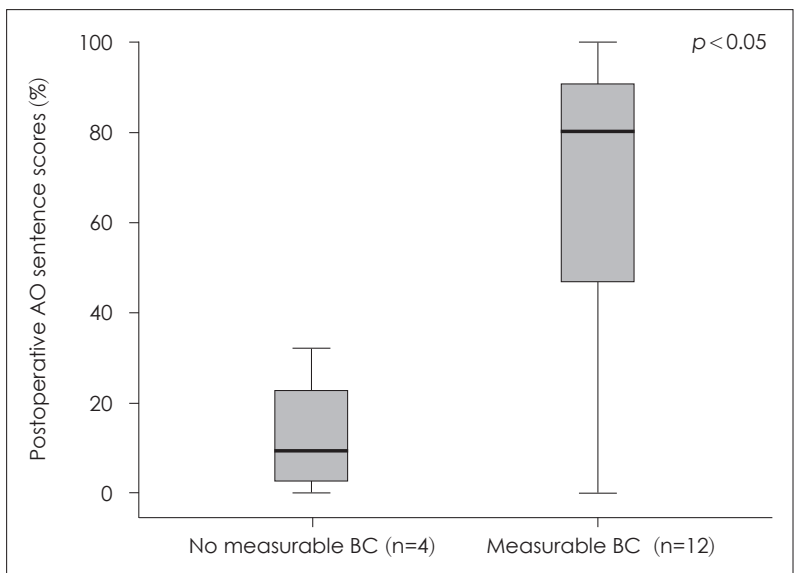

Fig. 4. The difference in the postoperative outcome regarding the presence or absence of measurable bone conduction in the implanted side. Patients with measurable bone conduction thresholds in the implanted ear $(n=4)$ demonstrated significantly better postoperative sentence scores than those with no measurable bone conduction threshold $(n=12)(p=0.03)$. AO: auditory-only, BC: bone conduction.

ing aid on the right side since 11 years of age. He was educated in a special school for deaf children. He had no measurable bone conduction in any of the frequencies preoperatively and his preoperative SIR score was 2. Although there was mild improvement of sentence scores in the AV condition from $20 \%$ to $43 \%$, no significant improvement could be achieved in the $\mathrm{AO}$ condition from $0 \%$ to $5 \%$. Patient 9 , implanted at the age of 37 years, demonstrated no improvement of sentence scores in the AV or AO settings, and the postoperative sentence scores evaluated 3 months following switch-on was $0 \%$. This patient exhibited no measurable bone conduction 


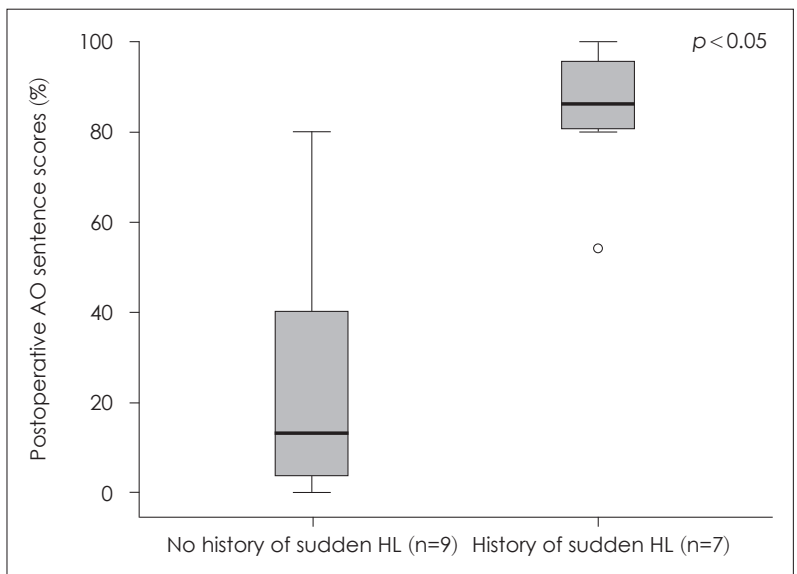

Fig. 5. The difference in the postoperative outcome regarding the presence or absence of a recent history of sudden aggravation of hearing loss. Patients with a recent history of sudden aggravation of hearing loss $(n=7)$ demonstrated significantly better postoperative sentence scores than those without $(n=9)(p=0.002)$. AO: auditory-only, HL: hearing loss.

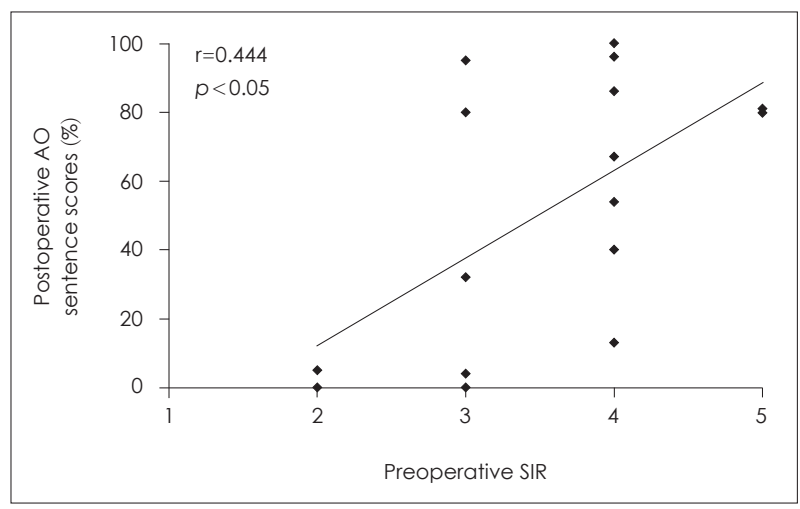

Fig. 6. The correlation between preoperative SIR scores and postoperative outcome. The preoperative SIR scores correlated significantly with postoperative sentence scores in auditory-only condition $(r=0.444, p=0.024)$. AO: auditory-only, SIR: speech intelligibility rating.

on pure tone audiometry with a low SIR score of 2 preoperatively, and also, she had discontinued use of hearing aids 10 years prior to CI because of no benefit and discomfort. Unfortunately, this patient was lost to follow-up afterwards prohibiting further postoperative evaluations.

\section{Discussion}

Significant improvement in auditory performance could be achieved following CI in patients with EVA carrying biallelic SLC26A4 mutations despite the delayed timing, irrespective of age. The overall CAP scores as well as word and sentence scores improved significantly. Although there have been many reports on the outcome of $\mathrm{CI}$ in patients with EVA, most of them focused on children and did not include the results of

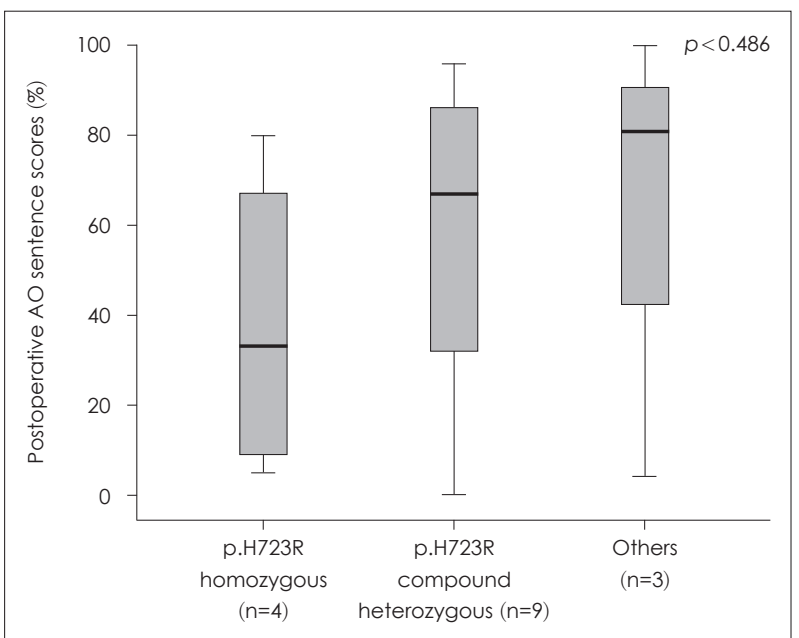

Fig. 7. The correlation between the type of SLC26A4 mutation and postoperative outcome. Although there was a tendency of lower postoperative sentence scores in the p.H723R homozygous mutation group, the difference was not statistically significant between the 3 types of SLC26A4 mutation $(p=0.486)$. AO: auditory-only.

genetic analysis. ${ }^{5,6,8,9,14,15)}$ There are few reports on the outcome of CI performed in the adult period in patients with EVA. Miyamoto, et al. ${ }^{7)}$ reported the outcome of $\mathrm{CI}$ in 14 adults and 9 children with EVA, and concluded that the auditory and speech recognition performance did not differ compared to control subjects. Another recent study analyzed the outcome of $\mathrm{CI}$ in 19 adults and 22 children with either nonsyndromic EVA or Pendred syndrome, and compared the results with the control group. ${ }^{20)}$ This study also suggested that there was no significant difference in the speech perception results among the EVA group, Pendred syndrome group, and the control group in adult implantees. ${ }^{20)}$ In both of these studies, the adult group consisted of both prelingual and postlingual deaf patients, mostly postlingual deaf adults in the former study, and the genetic data were not included. ${ }^{7,20)}$

Most of the patients with EVA and SLC26A4 mutations have pre- or perilingual hearing loss and acquire variable auditory and speech abilities depending on factors such as the degree of hearing loss, use of hearing aids, progressive nature of hearing loss, and communication modes. It is a challenge to precisely determine the prognostic factors of $\mathrm{CI}$ in this special entity of patients because the exact onset and progressive nature of their hearing loss is often hard to specify retrospectively. In determining the optimal time for $\mathrm{CI}$, the importance of regular longitudinal audiometric follow up has been emphasized. ${ }^{5,920)}$ Although patients with EVA usually perform better than prelingually deaf counterparts due to more exposure to normal speech patterns before progressing to profound 
hearing loss, individualized strategies are needed considering the variability in auditory outcome of $\mathrm{CI}$ in late implanted patients with early-onset hearing loss compared to postlingually deaf adults. ${ }^{5,10,13,21)}$

Several predictors of language development following CI have been reported including age at implantation, duration of hearing loss, degree of residual hearing at the time of surgery. ${ }^{22)}$ In this study, the various prognostic factors were analyzed that could be useful in candidacy selection and preoperative counseling in patients with EVA. First, when preoperative status of residual hearing was correlated with outcome, the presence of measurable bone conduction in the implanted ear and the level of PTA of the better ear demonstrated significant prognostic value. Although all of the patients included in this study had severe to profound hearing loss and a sentence score of less than $50 \%$, variable degrees of residual hearing were present especially in the low frequencies, frequently with an air-bone gap. It has been reported that approximately $20 \%$ of spiral ganglion cells are present in patients with EVA compared to normal subjects, which is more than the previously reported minimally required number of spiral ganglion cells to achieve auditory stimulation after CI. ${ }^{23)}$ The presence of a measurable bone conduction in the implanted side may reflect more reserved function of the hair cells and the spiral ganglion cells to be stimulated by the cochlear implant considering that there is often an airbone gap in the low frequencies in patients with EVA due to the third window effect. ${ }^{3)}$ Also, as Yang, et al. ${ }^{13)}$ have emphasized the importance of residual hearing in prelingually deaf adults regarding the postoperative performance after $\mathrm{CI}$, the preoperative PTA in the better ear was also significantly correlated with outcome in patients with EVA in this study.

When the pattern of hearing loss progression was analyzed in patients with EVA to evaluate its prognostic significance, the presence of a history of sudden aggravation of hearing loss was significantly related to better postoperative outcome. Seven patients had experienced recent aggravation of hearing loss within 3 years before $\mathrm{CI}$, meaning that short duration of severe to profound deafness and longer exposure to acoustic sounds are related to better auditory performance after CI. Sudden hearing loss in patients with EVA is known to be related to events such as head trauma, upper respiratory tract infections, valsalva maneuver and so forth. ${ }^{24)}$ Since it is difficult to have serial objective audiometric data in patients with long-term deafness, the presence of a recent history of sudden loss in hearing might provide clues about the duration of meaningful auditory experience.

In this study, several other factors that may reflect an adequate auditory input during the critical period for development of speech were also found to be associated with postoperative speech perception after CI. These factors include communication modes, continued use of hearing aids, and speech intelligibility. Previous studies have reported that patients who use oral communication and had received auditory-oral training together with continued use of hearing aids performed much better than those using total or sign communication. ${ }^{10,13)}$ Also, preimplant speech intelligibility has been reported to be highly correlated with postoperative outcome after CI. ${ }^{12,21)}$ Preimplant speech intelligibility can be a good reflection of the availability of early auditory experience, and van Dijkhuizen, et al. ${ }^{12)}$ suggested preoperative speech intelligibility to be a valid predictor of speech perception outcome with a cochlear implant in adults with prelingual deafness.

All of the patients in this study had biallelic mutations of the SLC26A4 gene. The frequency of common allelic mutations was similar to the previous reports on Koreans in which p.H723R and IVS7-2A $>\mathrm{G}$ were the most common mutations. ${ }^{25,26)}$ Lee, et al. ${ }^{26)}$ have reported that patients with p.H723R homozygous mutations had worse hearing, higher possibility of combined cochlear malformations, and less probability of hearing fluctuations compared to those carrying other type of mutations. Functionally, it was shown that the rate of pendrin expression at the plasma membrane and the anion exchange activities were lower in p.H723R transfected cells than those in cells transfected with p.T410M plasmids when using HEK 293 cells. ${ }^{26)}$ When the type of mutation of the SLC26A4 gene was correlated with postoperative auditory performance in this study, a tendency of lower postoperative sentence scores was observed in patients with p.H723R homozygous mutations in accordance with the results of phenotypic and functional analysis reported by Lee, et al. ${ }^{26)}$ This tendency could be explained in the way that earlier progression to profound hearing loss in patients with p.H723R mutations may lead to poorer outcome after CI. However, the difference did not reach statistical significance, which could be due to the small number of subjects included in this study or it may be that these differences in residual pendrin function caused by different genetic aberrations do not influence the outcome of CI. Previous studies have reported good outcome following $\mathrm{CI}$ in children with SLC26A4 mutations. ${ }^{1727)}$ More large scale studies are warranted to confirm the effect of genetics on the out- 
come of $\mathrm{CI}$

There are some limitations of this study. One is the difference in the time point when the postoperative outcome was evaluated. Although all of the patients were counseled strongly to follow the scheduled postoperative mapping and rehabilitation sessions, 3 of the patients did not undergo speech evaluations beyond 3 months following switch-on. It may be that patients with low auditory perception scores were less motivated to continue with the rehabilitation process. However, Snik, et al. ${ }^{11)}$ and others have demonstrated that congenitally deaf patients implanted during adulthood show obvious progression during the first few months of cochlear implant use, which plateau afterwards. ${ }^{28)}$ Therefore, we believe that the difference in the postoperative follow-up period probably did not have a major influence on the outcome. Another limitation is the small number of subjects included. Yet since there is limited data reporting the results of CI in EVA patients implanted beyond early childhood, we think that this study may be valuable in that a specific subset of patients with a common genetic cause was included. Lastly, it would have been better to include quality of life measures associated with hearing, which should be performed in future studies. ${ }^{11,21)}$ In addition, the rationale for including patients aged 12 years and older in this study was that the cortical auditory maturation is known to end by 12 years of age and that the outcome assessment after CI becomes reliable after the age of 12 years without the ceiling effect. ${ }^{29,30)}$

Despite the early-onset of hearing loss, significant improvement in auditory performance can be expected after CI in adolescent and adult patients with EVA and biallelic SLC26A4 mutations. The factors related to the level of residual hearing and speech exposure prior to CI including measurable bone conduction thresholds, preoperative PTA, the presence of recent history of sudden aggravation of hearing loss, and preoperative SIR scores were correlated with auditory outcome of CI. The type of SLC26A4 mutations did not reach statistical significance as a prognostic factor regarding auditory performance after CI. Significant prognostic factors should be considered in candidacy selection and preoperative counseling in these patients.

\section{Acknowledgments}

This research was supported by the Basic Science Research Program (2015R1A1A1A05001472) and the Bio \& Medical Technology Development Program (2013M3A9D5072551) of the National Research Foundation (NRF) funded by the Ministry of Science, ICT \& Future Planning.

\section{REFERENCES}

1) Campbell C, Cucci RA, Prasad S, Green GE, Edeal JB, Galer CE, et al. Pendred syndrome, DFNB4, and PDS/SLC26A4 identification of eight novel mutations and possible genotype-phenotype correlations. Hum Mutat 2001;17(5):403-11.

2) King KA, Choi BY, Zalewski C, Madeo AC, Manichaikul A, Pryor SP, et al. SLC26A4 genotype, but not cochlear radiologic structure, is correlated with hearing loss in ears with an enlarged vestibular aqueduct. Laryngoscope 2010;120(2):384-9.

3) Govaerts PJ, Casselman J, Daemers K, De Ceulaer G, Somers T, Offeciers FE. Audiological findings in large vestibular aqueduct syndrome. Int J Pediatr Otorhinolaryngol 1999;51(3):157-64.

4) Slattery WH 3rd, Luxford WM. Cochlear implantation in the congenital malformed cochlea. Laryngoscope 1995;105(11):1184-7.

5) Lee KH, Lee J, Isaacson B, Kutz JW, Roland PS. Cochlear implantation in children with enlarged vestibular aqueduct. Laryngoscope 2010; 120(8):1675-81.

6) Pakdaman MN, Herrmann BS, Curtin HD, Van Beek-King J, Lee DJ. Cochlear implantation in children with anomalous cochleovestibular anatomy: a systematic review. Otolaryngol Head Neck Surg 2012; 146(2):180-90.

7) Miyamoto RT, Bichey BG, Wynne MK, Kirk KI. Cochlear implantation with large vestibular aqueduct syndrome. Laryngoscope 2002;112 (7 Pt 1):1178-82.

8) Isaiah A, Lee D, Lenes-Voit F, Sweeney M, Kutz W, Isaacson B, et al. Clinical outcomes following cochlear implantation in children with inner ear anomalies. Int J Pediatr Otorhinolaryngol 2017;93:1-6.

9) Pritchett C, Zwolan T, Huq F, Phillips A, Parmar H, Ibrahim M, et al. Variations in the cochlear implant experience in children with enlarged vestibular aqueduct. Laryngoscope 2015;125(9):2169-74.

10) Caposecco A, Hickson L, Pedley K. Cochlear implant outcomes in adults and adolescents with early-onset hearing loss. Ear Hear 2012; 33(2):209-20.

11) Snik AF, Makhdoum MJ, Vermeulen AM, Brokx JP, van den Broek $P$. The relation between age at the time of cochlear implantation and long-term speech perception abilities in congenitally deaf subjects. Int J Pediatr Otorhinolaryngol 1997;41(2):121-31.

12) van Dijkhuizen JN, Beers M, Boermans PP, Briaire JJ, Frijns JH. Speech intelligibility as a predictor of cochlear implant outcome in prelingually deafened adults. Ear Hear 2011;32(4):445-58.

13) Yang WS, Moon IS, Kim HN, Lee WS, Lee SE, Choi JY. Delayed cochlear implantation in adults with prelingual severe-to-profound hearing loss. Otol Neurotol 2011;32(2):223-8.

14) Buchman CA, Copeland BJ, Yu KK, Brown CJ, Carrasco VN, Pillsbury HC 3rd. Cochlear implantation in children with congenital inner ear malformations. Laryngoscope 2004;114(2):309-16.

15) Papsin BC. Cochlear implantation in children with anomalous cochleovestibular anatomy. Laryngoscope 2005;115(1 Pt 2 Suppl 106):1-26.

16) Mey K, Bille M, Cayé-Thomasen P. Cochlear implantation in Pendred syndrome and non-syndromic enlarged vestibular aqueduct - clinical challenges, surgical results, and complications. Acta Otolaryngol 2016;136(10):1064-8.

17) Lai R, Hu P, Zhu F, Zhu G, Vivero R, Peng A, et al. Genetic diagnosis and cochlear implantation for patients with nonsyndromic hearing loss and enlarged vestibular aqueduct. J Laryngol Otol 2012;126(4): 349-55.

18) Song MH, Shin JW, Park HJ, Lee KA, Kim Y, Kim UK, et al. Intrafamilial phenotypic variability in families with biallelic SLC26A4 mutations. Laryngoscope 2014;124(5):E194-202.

19) Allen MC, Nikolopoulos TP, O'Donoghue GM. Speech intelligibility in children after cochlear implantation. Am J Otol 1998;19(6):742-6.

20) van Nierop JW, Huinck WJ, Pennings RJ, Admiraal RJ, Mylanus EA, Kunst HP. Patients with Pendred syndrome: is cochlear implantation 
beneficial? Clin Otolaryngol 2016;41(4):386-94.

21) Klop WM, Briaire JJ, Stiggelbout AM, Frijns JH. Cochlear implant outcomes and quality of life in adults with prelingual deafness. Laryngoscope 2007;117(11):1982-7.

22) Niparko JK, Tobey EA, Thal DJ, Eisenberg LS, Wang NY, Quittner $\mathrm{AL}$, et al. Spoken language development in children following cochlear implantation. JAMA 2010;303(15):1498-506.

23) Linthicum FH Jr, Anderson W. Cochlear implantation of totally deaf ears. Histologic evaluation of candidacy. Acta Otolaryngol 1991;111 (2):327-31.

24) Berrettini S, Forli F, Bogazzi F, Neri E, Salvatori L, Casani AP, et al. Large vestibular aqueduct syndrome: audiological, radiological, clinical, and genetic features. Am J Otolaryngol 2005;26(6):363-71.

25) Park HJ, Lee SJ, Jin HS, Lee JO, Go SH, Jang HS, et al. Genetic basis of hearing loss associated with enlarged vestibular aqueducts in Koreans. Clin Genet 2005;67(2):160-5.

26) Lee HJ, Jung J, Shin JW, Song MH, Kim SH, Lee JH, et al. Correlation between genotype and phenotype in patients with bi-allelic SLC26A4 mutations. Clin Genet 2014;86(3):270-5.

27) Wu CC, Lee YC, Chen PJ, Hsu CJ. Predominance of genetic diagnosis and imaging results as predictors in determining the speech perception performance outcome after cochlear implantation in children. Arch Pediatr Adolesc Med 2008;162(3):269-76.

28) Santarelli R, De Filippi R, Genovese E, Arslan E. Cochlear implantation outcome in prelingually deafened young adults. A speech perception study. Audiol Neurootol 2008;13(4):257-65.

29) O'Donoghue GM, Nikolopoulos TP, Archbold SM. Determinants of speech perception in children after cochlear implantation. Lancet 2000;356(9228):466-8.

30) Ponton CW, Don M, Eggermont JJ, Waring MD, Masuda A. Maturation of human cortical auditory function: differences between normal-hearing children and children with cochlear implants. Ear Hear 1996;17(5):430-7. 